by adiabatic demagnetization, and the problems of relating the magnetic and thermodynamic temperature scales. This chapter really contains the reasons for the major changes made later in the book. For example, the title of the former chapter on "The Nernst Heat Theorem" has been changed to "The Third Law of Thermodynamics". There the evidence accumulated from the study of helium equilibria, superconduction and adiabatic demagnetization is shown to indicate that the entropy difference between the possible states of a system vanishes as the system approaches absolute zero, and to justify the changed status of this theorem.

There is an entirely new chapter on higher-order phase transitions, and here two important cases have been treated as illustrations of a general principle. These are the second-order transitions of liquid helium at its lambda point, and of a metal to the superconducting state. Second-order analogues of the Clausius-Clapeyron equation are first derived from the Gibbs function or its magnetic equivalent, and these are seen to contain the parameters involved, and to be consistent with the observations.

At the end of the chapter on the second law of thermodynamics, Carathéodory's principle is mentioned as the logical basis of the analytical treatment of the second law. It is prcper that the student should be made to consider whether the concept of entropy, introduced via one-component systems operating Carnot cycles, is, in fact, applicable to systems with more than one component. It appears that the principle, which justifies this generalization, follows at once from Joule's experiments, as the text states; but it might have been well to add a few lines of explanation at this point, since the student's real difficulty often lies in the step between experiment and analysis.

In devoting himself to the revision of this indispensable book, Dr. Millor has done a valuable piece of work; and the publishers and printers must be congratulated on a standard of production which matches the excellence of the earlier editions.

(x. R. NOAKES

\section{A PHOTOGRAPHER IN THE ANTARCTIC}

Antarctic Isle: Wild Life in South Georgia By Niall Rankin. Pp. $383+138$ plates. (London and Glasgow: Wm. Collins, Sons and Co., Ltd., 1951.) 25s, net.

TIALL RANKIN in his earlier book, "British 1 Divers", set a high standard for his following works, and he has now written a book which will be prized alike by the scientific-minded and the nonscientific-minded of his readers. 'This time he takes his reader far afield, to his "Antarctic Isle". From his home in the Isle of Mull, Colonel Rankin made an ambitious expedition to South Georgia, his small vessel being a converted Royal National Lifeboat, 42 $\mathrm{ft}$. long and of $11 \mathrm{ft}$. beam, which was carried to South Georgia on the deck of a large 23,000-ton vessel used as a floating whale factory. The other members of the crew were two young Shetland seamen. South Georgia, 100 miles in length and 30 in breadth, is the sea-bird lover's paradise, and Colonel Rankin's remarkable photographs bring the island vividly before the reader's mind. Although bird life is so plentiful, there are in South Georgia only three phanerogamic plants - a small Antarctic buttercup (Ranunculus biternatus), a bedstraw (Galium antarcticum) and two burnets, the larger of the two (Acoena ascendens) being peculiar to South Georgia.

One of the most arresting chapters in the book is that on the wandering albatross, a great bird with a wing span approaching $11 \mathrm{ft}$. and a weight up to $27 \mathrm{lb}$. At a colony of these birds, Colonel Rankin made valuable observations. He believed the incubation period to be 70-73 days. Six days elapsed between the first chipping of one egg and the hatching of the bird. The young albatrosses (they remain in the nest, still in down, throughout the whole of their first winter) were regularly weighed. One at birth was $13 \mathrm{oz}$.; at the end of a week it was $22 \mathrm{oz}$., at 22 days $4 \mathrm{lb} .4 \mathrm{oz}$, and at 31 days $6 \mathrm{lb} .11 \mathrm{oz}$. The author gives the record of a wandering albatross's flight of no fewer than 3,150 nautical miles in 12 days.

This book combines good writing with outstanding photography. Many of the observations on the birds of South Georgia are new, and the account of the courtship of the wandering albatross is a piece of remarkably descriptive writing. Colonel Rankin was unsuccessful in his efforts to discover the egg of the snow petrel, but there is (p. 270) a fine account of the masterly flight of this, the most hardy of Antaretic petrels. Birds occupy only a part of the book. There are chapters on the whales and the seals, and the author does well to re-tell Sir Ernest Shackleton's epic voyage with five companions in an open boat from Elephant Island to South Georgia over more than eight hundred miles away through tempestuous seas and in bitter cold. That voyage was one of the most hazardous ever successfully undertaken by man, and at its close the tired men had to mako a crossing (the only one ever made) of the snowy heights of South (Xeorgia to reach the sealing station there.

The photographs which illustrate this book are of so high a standard that it is difficult to single out any for special praise. To my mind, those showing the courtship display of the wandering albatross and that of Wilson's petrels in flight are perhaps the best. Of the photographs of scenery (one shows a 9,000-ft. peak untrodden by the foot of man), the most remarkable is that (plate 107) showing a gust of wind estimated at 115 miles an hour on the point of reaching the author's craft at anchor. Colonel Rankin was ashore at the time, and took the photograph crouching on all fours. He tells us that he feared his craft was doomed. Seton GoRdon

\section{BIRDS OF GREENLAND}

\section{Grønlands Fugle (The Birds of Greenland)}

Text by Finn Salomonsen; plates by Gitz-Johansen. Part 2. Pp. 159-348+ 19 plates. (København: Ejnar Munksgaard, 1951.) 66s.; 9 dollars.

7 HE second part of this useful work deals with the ptarmigan, wading birds, skuas and gulls. The ptarmigan is very common and is treated in great detail, and there are new and interesting observations. Dr. F. Salomonsen recognizes three races in Greenland which are found from sea-level to the ice-cap and as far as lat. $82^{\circ} 46^{\prime} \mathrm{N}$., where Captain Feilden, naturalist in the Alert, collected a specimen in 1876 and on the label wrote "The northernmost bird ever collected by man". Though this record still holds good for the ptarmigan, a turnstone and a long-tailed 